\title{
Industrial Composting of Sewage Sludge: Study of the Bacteriome, Sanitation, and Antibiotic-Resistant Strains
}

\section{Juan A. López-González*, María J. Estrella-González, Rosario Lerma-Moliz, Macarena M. Jurado, Francisca Suárez-Estrella and María J. López}

Unit of Microbiology, Department of Biology and Geology, CITE II-B, Agrifood Campus of International Excellence ceiA3, CIAIMBITAL, University of Almería, Almería, Spain

Wastewater treatment generates a huge amount of sewage sludge, which is a source of environmental pollution. Among the alternatives for the management of this waste, industrial composting stands out as one of the most relevant. The objective of this study was to analyze the bacterial population linked to this process and to determine its effectiveness for the reduction, and even elimination, of microorganisms and pathogens present in these organic wastes. For this purpose, the bacteriome and the fecal bacteria contamination of samples from different sewage sludge industrial composting facilities were evaluated. In addition, fecal bacteria indicators and pathogens, such as Salmonella, were isolated from samples collected at key stages of the process and characterized for antibiotic resistance to macrolide, $\beta$-lactam, quinolone, and aminoglycoside families. 16S rRNA phylogeny data revealed that the process clearly evolved toward a prevalence of Firmicutes and Actinobacteria phyla, removing the fecal load. Moreover, antibiotic-resistant microorganisms present in the raw materials were reduced, since these were isolated only in the bio-oxidative phase. Therefore, industrial composting of sewage sludge results in a bio-safe final product suitable for use in a variety of applications.

Keywords: biosolids, fecal contamination, metagenomics, antibiotic resistance, compost, enterobacteria, clostridia, fecal enterococci

\section{INTRODUCTION}

The accelerated appearance of antibiotic resistance has become a global health problem (Abadi et al., 2019; Mobarki et al., 2019). In fact, it is estimated that by 2050 there will be 10 million deaths as a result of this problem (He et al., 2020). The situation is aggravated by the spread caused by the continuous generation of waste of anthropogenic origin (Karkman et al., 2018). These include, among others, sewage sludge, which contains heavy metals, organic compounds, pathogens (Lamastra et al., 2018), and traces of antibiotics that promote the emergence of antibiotic-resistant bacteria (ARGs) (Sun et al., 2019; Urra et al., 2019). After treatment, this waste can be used as fertilizer and for soil bioremediation (Eid et al., 2018), as well as to obtain energy and heat (Abuşoğlu et al., 2017). Therefore, a good management of these biosolids is crucial to avoiding the environmental and sanitary threats derived of the application of improperly treated sewage sludge (Kacprzak et al., 2017). 
Current alternatives for the treatment of sewage sludge include composting, anaerobic digestion, and thermochemical processes, such as incineration, pyrolysis, or gasification (Raheem et al., 2018; Gao et al., 2020). Composting is considered one of the best options due to its sustainability and integration into circular bioeconomy concept, which is what the current European system is committed to Razza et al. (2018). This process generated a safe and stable bioproduct, the compost, which can be used as organic fertilizer (Soobhany et al., 2017). Moreover, the high temperatures reached during the process eliminate possible pathogens and, in addition, could reduce ARGs present in the raw materials (Zittel et al., 2020).

The culture techniques only estimate about $3 \%$ of the microbiota present in an environmental sample (Rubin, 2008). The development of "omics" as an alternative to traditional methods has allowed a deeper understanding of the microbiota present in a given habitat. Metagenomic analysis, through the use of bioinformatics tools, makes it possible to know even the non-culturable microbiota. In this way, it is possible to study in a more exhaustive way the microbial evolution that occurs during any environmental process, as it is the case of composting (Estrella-González et al., 2020b; Ma et al., 2020). Thanks to these tools, the presence of certain microbial groups can be effectively tested. This is particularly interesting since prokaryotes are mainly responsible for the degradation of toxic substances and the reduction of ARGs (Yadav and Kapley, 2019; Zhang et al., 2020). In this context, several authors relate through their research the efficacy of composting to remove ARGs (Su et al., 2015; Zhang et al., 2019; Tang et al., 2021; Zhu et al., 2021). Employing metagenomics for the analysis of swine manure composting, it has been reported that the host microbiota influences the depletion of these genes more than the environmental factors of the process itself (Zhang et al., 2018). Furthermore, in the disappearance of some genera such as Acinetobacter or Pseudomonas could also be related (Wu et al., 2020). Therefore, the possibility of corroborating these promising results on industrial composting of sewage sludge is of significant relevance. For this purpose, conventional cultivation techniques and culture-independent techniques can be successfully combined.

Based on the above, the main objectives of this work were (1) to analyze the evolution of the process in three industrial sewage sludge composting facilities using basic monitoring parameters; (2) to study the bacteriome of all processes; (3) to evaluate the fecal bacterial contamination levels during composting, through the study of indicator parameters, as well as human pathogens, using culture-dependent techniques; and (4) to characterize the antibiotic resistance through the industrial composting of a group of strains isolated from the positive results of the evaluation fecal load.

\section{MATERIALS AND METHODS}

\section{Sampling Treatment}

Samples were collected from three industrial sewage sludge composting Spanish facilities located in the Southeast of Spain
(SS1, SS2, and SS3). SS1 and SS2 operated with open air and turned windrows. On the other hand, SS3 used an in-vessel tunnel composting system with turning by augers. The composting process lasted for 3 months in all cases, with a bio-oxidative phase of 2 months for SS1 and SS2 and 1 month for SS3. The composting mixture consisted of sewage sludge + straw $(1: 1 \mathrm{v} / \mathrm{v})$ for SS1, sewage sludge + pruning wastes $(1: 1 \mathrm{v} / \mathrm{v})$ for SS2, and dried sewage sludge + pruning wastes $(1: 2 \mathrm{v} / \mathrm{v})$ for SS3. All sewage sludge consisted of activated sludge. The different samples represented the most characteristic phases of the composting process. These were samples from raw material (RM), mesophilic phase (MES), thermophilic phase (TER) $\left(>60^{\circ} \mathrm{C}\right)$, cooling phase (COOL), maturation phase (MAT), and final product (FP). At each stage of the process, 300-g subsamples were collected from different points and depths of the piles (with depths of $0.5 \mathrm{~m}, 1.5 \mathrm{~m}$, and the bottom). These subsamples were then mixed to constitute $3 \mathrm{~kg}$ of representative sample. Samples for control parameter analysis were stored at $-20^{\circ} \mathrm{C}$ in vacuum bags. Samples for analysis of biological parameters were fresh processed after sampling. For the study of carbon, nitrogen, and organic matter, the material was dried and ground up to a particle size $<1 \mathrm{~mm}$.

\section{Control Parameter Analysis}

The parameters of control were carried out in all the samples. Moisture was determined by drying at $100^{\circ} \mathrm{C}$ for $24 \mathrm{~h}$ with $20 \mathrm{~g}$ of the sample. All the data were expressed on a dry-weight basis. The $\mathrm{pH}$ and electrical conductivity were analyzed from a 1:10 dilution of the samples in distilled water using Crison BASIC 30 (Crison Instruments, S.A., Barcelona, Spain). In the case of bulk density (BD), each sample was placed in a PVC cylinder of known dimensions. The weights before and after being dried in an oven at $60^{\circ} \mathrm{C}$ for $24 \mathrm{~h}$ were used to calculate the BD with the following expression: $\mathrm{BD}\left(\mathrm{g} \mathrm{cm}^{-3}\right)=$ dry sample weight (g)/cylinder volume $\left(\mathrm{cm}^{3}\right)$. The $\mathrm{C} / \mathrm{N}$ ratio was obtained from the elemental determination of the carbon and nitrogen contents by combustion of the sample at $950^{\circ} \mathrm{C}$ using an Elementar Vario Micro CHNS (Elementar Analysensysteme GmbH, Hanau, Germany). The organic matter was determined by incineration at $550^{\circ} \mathrm{C}$ for $3.5 \mathrm{~h}$.

\section{Fecal Contamination Evaluation}

The bacterial fecal load was analyzed in SS1 using indicators of fecal contamination and human pathogens of interest in sewage sludge (total coliforms, fecal coliforms, Escherichia coli, fecal enterococci, sulfite-reducing clostridia, and presence of Salmonella and Listeria). For quantification, serial dilutions in $0.9 \%$ saline solution were prepared with the sample and inoculated in specific medium for each microbial group. The quantification of coliforms and fecal enterococci was performed using the Most Probable Number (MPN) method. In the case of coliforms, lactose broth (Scharlab, S.L., Barcelona, Spain) medium with bromocresol purple with the Durham tube was used. The temperature of incubation was different between total coliform, $37^{\circ} \mathrm{C}$, and fecal coliform, $44.5^{\circ} \mathrm{C}$. The presence of E. coli was determinate by plating on EMB agar (Panreac, ITW, Chicago, IL, United States) using the positive fecal coliform 
tubes. Rothe broth (Scharlab, S.L., Barcelona, Spain) was used to count fecal enterococci at $37^{\circ} \mathrm{C}$. These were confirmed by Gram stain. The sulfite-reducing clostridia group was quantified using the method described by Huong et al. (2014), and after incubation at $37^{\circ} \mathrm{C}$ under anaerobic conditions, black colonies were counted. All these cultures were incubated for 24-48 h. The detection of Salmonella and Listeria was performed using the pre-enrichment technique by placing $25 \mathrm{~g}$ of sample in $225 \mathrm{ml}$ of Buffered Peptone Water (AppliChem, ITW Reagents, IL, United States) for $24 \mathrm{~h}$ at $37^{\circ} \mathrm{C}$. Then, in the case of Salmonella, $1 \mathrm{ml}$ was added to Selenite Cystine broth tubes (Thermo Fisher Scientific, Waltham, MA, United States) and incubated for $18 \mathrm{~h}$ at $37^{\circ} \mathrm{C}$. This culture was used to inoculate Hektoen agar (Panreac, ITW, IL, United States) plates by streaking, and after incubation for $24 \mathrm{~h}$ at $37^{\circ} \mathrm{C}$, green colonies with a blackened central zone were confirmed on API 20E (biomerieux, Marcy-l'Étoile, France). For Listeria, Fraser broth (Merck, Darmstadt, Germany) was used to promote the growth of this pathogen. Suspected Listeria colonies were detected in PALCAM agar (Merck, Darmstadt, Germany), and then they were confirmed with an API test 07887Q (biomerieux, Marcyl'Étoile, France). Two strains of Listeria, L. innocua ATCC 33090, and L. monocytogenes ATCC 13932, were used as controls in this biochemical characterization test.

\section{Detection of Listeria by qPCR}

To correlate the results obtained for Listeria with culture technique, a qPCR was performed using the iQ-Check Listeria spp. Kit (Bio-Rad Laboratories, Inc., Hercules, CA, United States). Previously, pre-enrichment cultures were obtained by placing $25 \mathrm{~g}$ of the SS1 sample in Listeria Special Broth (LSB) medium (Bio-Rad Laboratories, Inc., Hercules, $\mathrm{CA}$, United States) and incubated at $37^{\circ} \mathrm{C}$ for $24 \mathrm{~h}$ for preenrichment. Once the DNA was extracted from pre-enrichment culture according to the kit instructions, a real-time PCR system CFX Connect Real-Time (Bio-Rad Laboratories, Inc., Hercules, CA, United States) was used with the following thermal profile: $10 \mathrm{~min}$ at $95^{\circ} \mathrm{C}, 49$ cycles of $15 \mathrm{~s}$ at $95^{\circ} \mathrm{C}, 20 \mathrm{~s}$ at $58^{\circ} \mathrm{C}$, and $30 \mathrm{~s}$ at $72^{\circ} \mathrm{C}$. The samples having a $C q$ value of $26 \leq C q \leq 36$ were given as positive for the FAM fluorophore. Apart from the kit positive control, the strains L. innocua ATCC 33090 and L. monocytogenes ATCC 13932 were used as additional controls.

\section{Antibiotic-Resistant Characterization}

A collection of pure cultures was obtained from each positive result of the fecal evaluation and detection of the presence of pathogens described in section "Fecal Contamination Evaluation." These strains were subjected to an evaluation of antibiotic resistance based on the method described by Kirby-Bauer (Bauer et al., 1966), which studies the sensitivity of a microorganism to an antibiotic or chemotherapeutical agent (antibiogram). For this purpose, disks impregnated with antibiotics (Thermo Fisher Scientific, Waltham, MA, United States) of the $\beta$-lactam, macrolide, quinolone, and aminoglycoside families at a known concentration were used against the growth of the strains of the collection obtained. First, a culture of each strain was obtained in nutrient broth (Panreac,
ITW, IL, United States) and adjusted equivalent to 0.5 on the McFarland scale. Then, these cultures were mass inoculated with sterile swab in the surface of Mueller-Hinton (Panreac, ITW, IL, United States) and disks of the antibiotics were put in the plate. Three strains (E. coli ATCC 13706; Salmonella enterica ATCC 10708; Enterococcus faecalis ATCC 33186) lacking antibiotic resistance acquired were used as controls. After incubation for $18 \mathrm{~h}$ at $37^{\circ} \mathrm{C}$, the growth inhibition halo was measured. The strains with no inhibition halo were considered resistant.

\section{Sequencing of the 16S rRNA Gene and Data Processing}

DNA extraction was performed using the DNeasy PowerSoil DNA isolation kit (Qiagen N.V., Hilden, Germany). The sequencing was performed on a MiSeq PE300 run (Illumina Inc., San Diego, CA, United States) at AllGenetics and Biology SL (La Coruña, Spain). A total of 54 samples were processed corresponding to 3 composting plants $\times 6$ samplings $\times 3$ replicates. The primers used for the amplification of bacterial DNA for sequencing were as follows: Bakt 341F (5'CCT ACG GGN GGC WGC AG 3') and Bakt 805R (5' GAC TAC HVG GGT ATC TAA TCC $\left.3^{\prime}\right)$. These primers amplified the variable regions 3-4 (V3-V4) of the 16s rRNA gene with an expected size of $530 \mathrm{pb}$. Blank and negative controls were used during the process to check for possible crosscontamination and contamination problems during library construction, respectively. The quality of the demultiplexed FASTQ files was verified by FastQC software (Andrews, 2010). Paired-end assembly of the R1 and R2 reads was performed with FLASH (Magoč and Salzberg, 2011), with a minimum length overlap of 30 base pairs. Sequences were processed using the QIIME2 pipeline (Bolyen et al., 2019). In short, reads were imported, quality filtered, and dereplicated with the q2-dada2 option (Callahan et al., 2016). The processed sequences were used for all the downstream analyses. The database used was Silva 132 (for taxonomy assignment).

\section{Statistical Analysis}

The parameters analyzed were performed in triplicate, using the mean for the presentation of the data. The physicochemical and fecal contamination parameters and biodiversity indices obtained were subjected to statistical analysis using Statgraphics Centurion XVIII.I (StatPoint Technologies Inc., Warrenton, VA, United States). Discriminant analysis was used to assess the adequacy of the classification of the composting facilities, in order to find simple equations for estimation of the development of stages of these composting processes from easily analyzable parameters. For this purpose, all physicochemical parameters and biodiversity indices measured were used. RStudio (RStudio Inc., AGPL v3) was used to represent correlation analyses, 16S rRNA phylogeny data, and boxplots for biodiversity indices.

\section{Data Availability}

Sequences are stored in the MG-RAST public repository, available by Accession Number PRJNA769273. The whole 
datasets generated and analyzed during the current study are available from the corresponding author on reasonable request.

\section{RESULTS}

\section{Development of Industrial Composting of Sewage Sludge}

The control parameters monitored during the composting processes are shown in Figures 1A-F. These parameters inform about the correct evolution of the process and included moisture, organic matter, temperature, $\mathrm{pH}$, electrical conductivity, $\mathrm{C} / \mathrm{N}$ ratio, and $\mathrm{BD}$. The process started with values of moisture in RM belonging to SS2 and SS3 around $65-70 \%$ (66.37\% in SS2 and $67.67 \%$ in SS3), while it was higher $(81.65 \%)$ in SS1. This parameter decreased during composting in the three facilities analyzed. The organic matter reduced around $30-50 \%$ when the maturation phase was reached due to the mineralization. In all facilities, thermophilic conditions above $65^{\circ} \mathrm{C}$ were reached. In the case of $\mathrm{pH}$, there were slight increases during the process
A

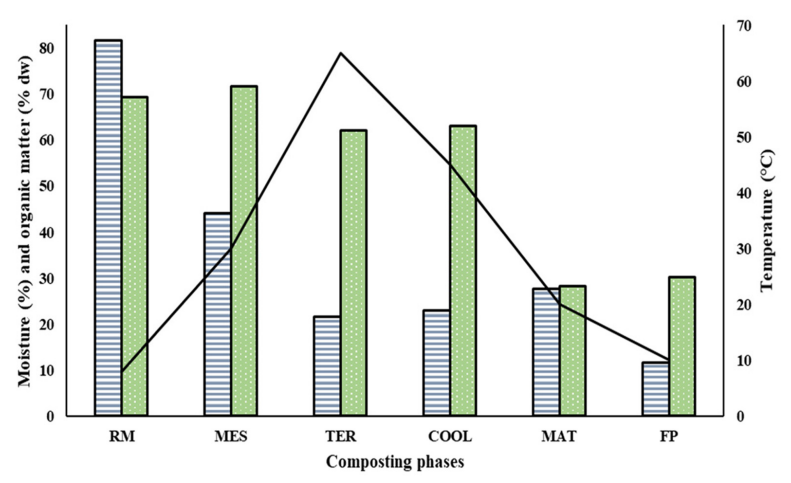

C

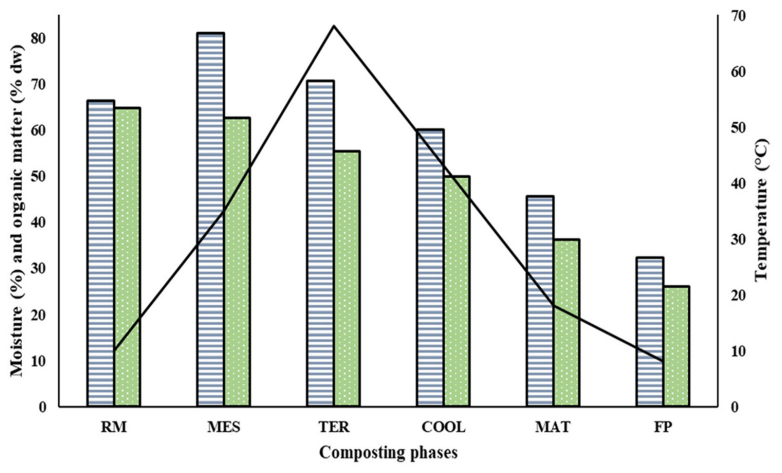

E

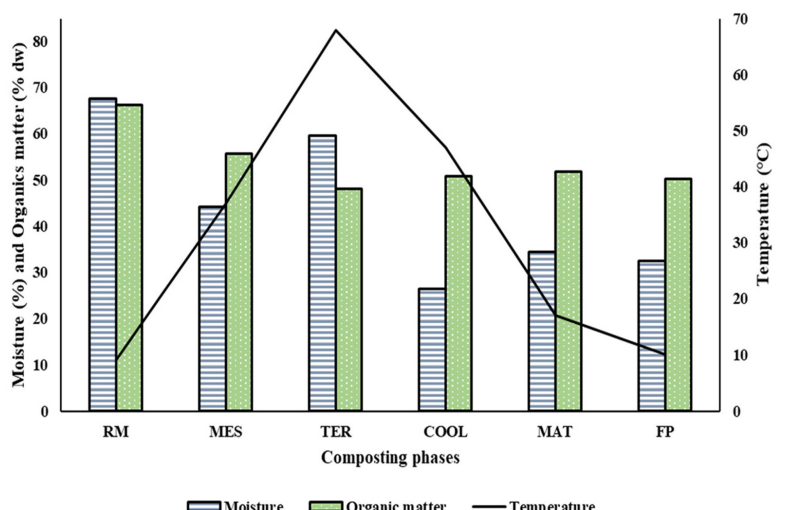

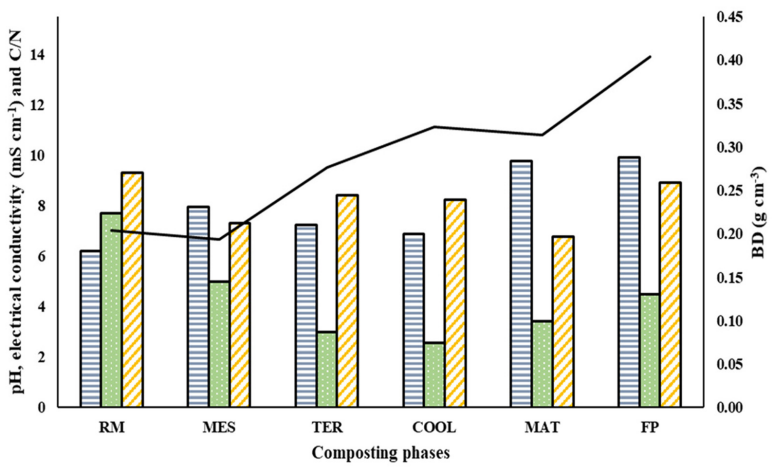

D

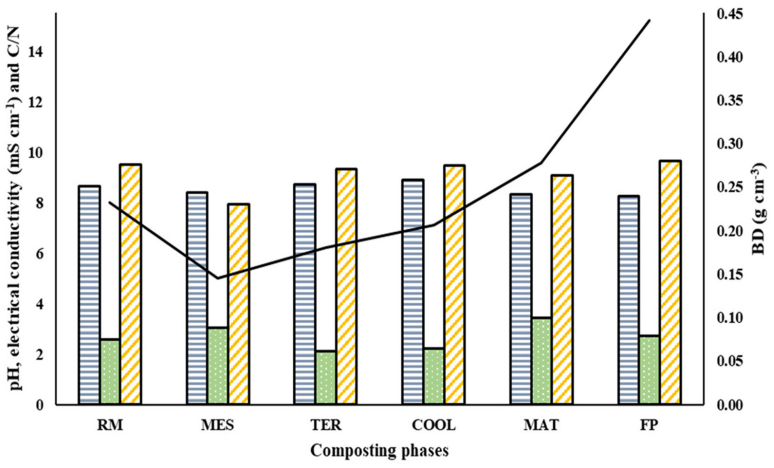

F

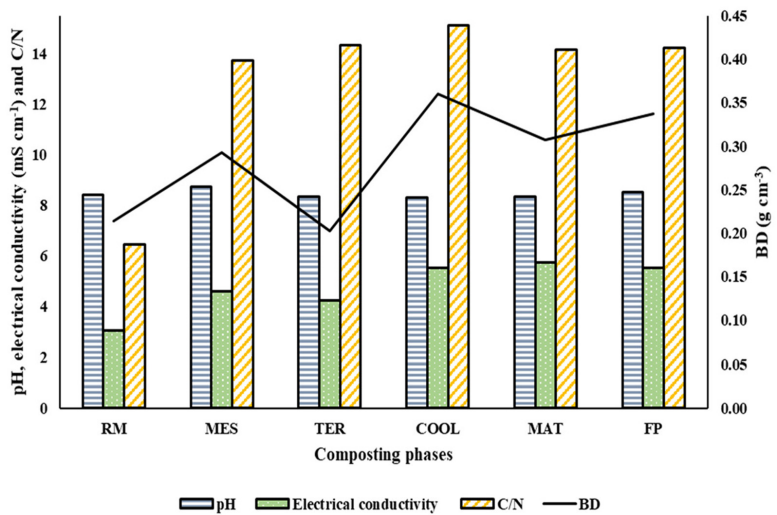

FIGURE 1 | Control parameters analysis. Moisture (\%), organic matter (\% dw), and temperature $\left({ }^{\circ} \mathrm{C}\right)$ are in Panels $(\mathbf{A}, \mathbf{C}, \mathbf{E}) ; \mathrm{pH}$, electrical conductivity $\left(\mathrm{mS} \mathrm{cm}{ }^{-1}\right)$, C/N, and BD (bulk density) $\left(\mathrm{g} \mathrm{cm}^{-3}\right.$ ) are in Panels (B,D,F). Panels (A,B) represent SS1; Panels (C,D) represent SS2; Panels (E,F) represent SS3. SS1, SS2, and SS3 represent each of the sampled sewage sludge composting facilities. 
up to values of $8.91,8.26$, and 8.52 units in SS1, SS2, and SS3, respectively, in the final compost. The electrical conductivity gradually decreased until the beginning of the maturation stage, from which it progressively increased up to final established values of $4.5,2.72$, and $5.52 \mathrm{mS} \mathrm{cm}^{-1}$ in SS1, SS2, and SS3, respectively. The highest data of the $\mathrm{C} / \mathrm{N}$ ratio was obtained in $\mathrm{SS} 3$, in which at the end of the bio-oxidative phase, values above 13 were reached. The $\mathrm{C} / \mathrm{N}$ ratio in SS1 and SS2 was lower than in SS3, and the value was less than 10 parts of carbon to 1 part of nitrogen remaining practically constant throughout the process. $\mathrm{BD}$ recorded some increases in the bio-oxidative phase and in the maturation phase, but it rose in the final product in all facilities reaching values of $0.40,0.44$, and $0.34 \mathrm{~g} \mathrm{~cm}^{-3}$ in SS1, SS2, and SS3, respectively.

\section{Fecal Contamination}

The fecal contamination was evaluated in SS1, and the results are shown in Table 1. In the coliform group, there was an initial increase followed by a decrease and stabilization at the end of the process. The maximum levels of the three fecal indicators analyzed were reached at the MES phase, with log units of total coliforms and fecal coliforms of 5.81 and 2.45 $\log \left(\mathrm{cfu} \mathrm{g}^{-1}\right)$, respectively. In this sampling phase, the entire fecal coliform count corresponded to E. coli species. The lowest microbial quantification was obtained in FP, with a value of 0.68 $\log$ units for both the total coliform and fecal coliform groups. E. coli was no longer detected since thermophilic conditions were reached. In the case of fecal enterococci, a significant increase was observed in the bio-oxidative phase (MES + TER) where counts above 3 log units were reached, decreasing afterward to reach $2.30 \log$ units in the final composts. Sulfite-reducing clostridia showed a stabilization in the first stages of the process until a cooling phase was established. In that sampling, the higher counts [3.14 $\left.\log \left(\mathrm{cfu} \mathrm{g}^{-1}\right)\right]$ of this group were obtained. Salmonella was detected in the TER and COOL samplings. This pathogen was absent in the final product. Listeria was exempt in the whole process according to both culture techniques and qPCR results.

\section{$16 S$ rRNA Phylogeny Comparative}

The bacterial richness and abundance (Figure 2) of each sample were studied using the Chaol and Shannon indexes, respectively. The maximum values for both indexes in SS1 and SS3 were found in the RM and COOL phases, of around 400-555 for richness and between 7 and 8 for the Shannon index. In SS2, the highest Chao 1 value was obtained in the COOL stage (599) and the highest Shannon values were reached in RM (7.02) and COOL (7.5). The lowest values for richness and abundance in both SS1 and SS3 were observed in the final samples (MAT and FP). At these phases, the Chaol index was around 180-195 and 280-285, in SS1 and SS3, respectively. With respect to the Shannon index, the data reached a maximum of 6.50 at maturation in SS1 and 5.72 in the final compost. The sample with the lowest richness and abundance for SS2 was TER in both indexes.

Figure 3 shows the results of relative abundance of bacterial taxonomic assignation obtained after the 16S rRNA phylogeny analysis of each phase of the different industrial-scale sewage sludge composting processes. The three processes studied showed very different profiles. Globally, the bacteria at the dominant phylum level were Firmicutes (33.30\%), Proteobacteria (20.70\%), Chloroflexi (12.71\%), Bacteroidetes (12.38\%), and Actinobacteria $(10.08 \%)$. However, the relative abundances of each sample were clearly different. In SS1, SS2, and SS3, the order Bacillales was present with percentages of $25.15,19.67$, and 73.50 , respectively. In addition, in both SS1 and SS3, the order Streptosporangiales was detected. SS1 contained a percentage of 66.15 and $9.82 \%$ in SS3. In the case of SS2, the phylum Proteobacteria was the dominant phylum, divided into two families: Pseudomonadales (48.24\%) and Alteromonadales (15.05\%). Despite the ascribed differences between the facilities studied, there was a clear pattern of biodiversity loss in all cases. Once the thermophilic phase was overcome, the results showed a significant increase in the predominance of Firmicutes.

\section{Discriminant and Correlation Analysis}

Several statistical analyses were performed with the results obtained. Figure 4 shows two discriminant analyses. The first discriminant analysis (Figure 4A) presented two discriminant functions responsible for more than $72 \%$ of the variability of the data. The results were grouped into 3 data sets: one corresponding to the initial phase of the processes (RM), a second group formed by the data related to the bio-oxidative phase (MES + TER), and a third group including the data corresponding to the stabilization and humification phase $(\mathrm{COOL}+\mathrm{MAT}+\mathrm{FP})$. Therefore, despite the heterogeneity of the data in relation to the starting materials and the working conditions of each facility, the data were appropriately grouped

TABLE 1 | Fecal contamination of SS1.

\begin{tabular}{|c|c|c|c|c|c|c|c|}
\hline Composting phase & Total $^{1}$ coliforms & Fecal $^{1}$ coliforms & E. coli ${ }^{1}$ & Fecal enterococci ${ }^{1}$ & Sulfite $^{2}$-reducing clostridia & Salmonella ${ }^{3}$ & Listeria $^{3}$ \\
\hline $\mathrm{RM}$ & 1.61 & 1.12 & 0 & 0.68 & 1.79 & - & - \\
\hline MES & 5.81 & 2.45 & 2.45 & 3.27 & 1.88 & - & - \\
\hline TER & 3.04 & 1.33 & 0 & 2.55 & 1.20 & + & - \\
\hline COOL & 2.93 & 1.03 & 0 & 2.27 & 3.14 & + & - \\
\hline MAT & 2.68 & 1.19 & 0 & 2.79 & 0.33 & - & - \\
\hline FP & 0.68 & 0.68 & 0 & 2.30 & 0.90 & - & - \\
\hline
\end{tabular}

${ }^{1}$ Calculated with the most probable number (MPN) and expressed in log $\left(c f u g^{-1}\right)$.

${ }^{2}$ Calculated based on log (cfu $\left.\mathrm{g}^{-1}\right)$.

${ }^{3}$ Determination of the presence $(+)$ or absence (-). 

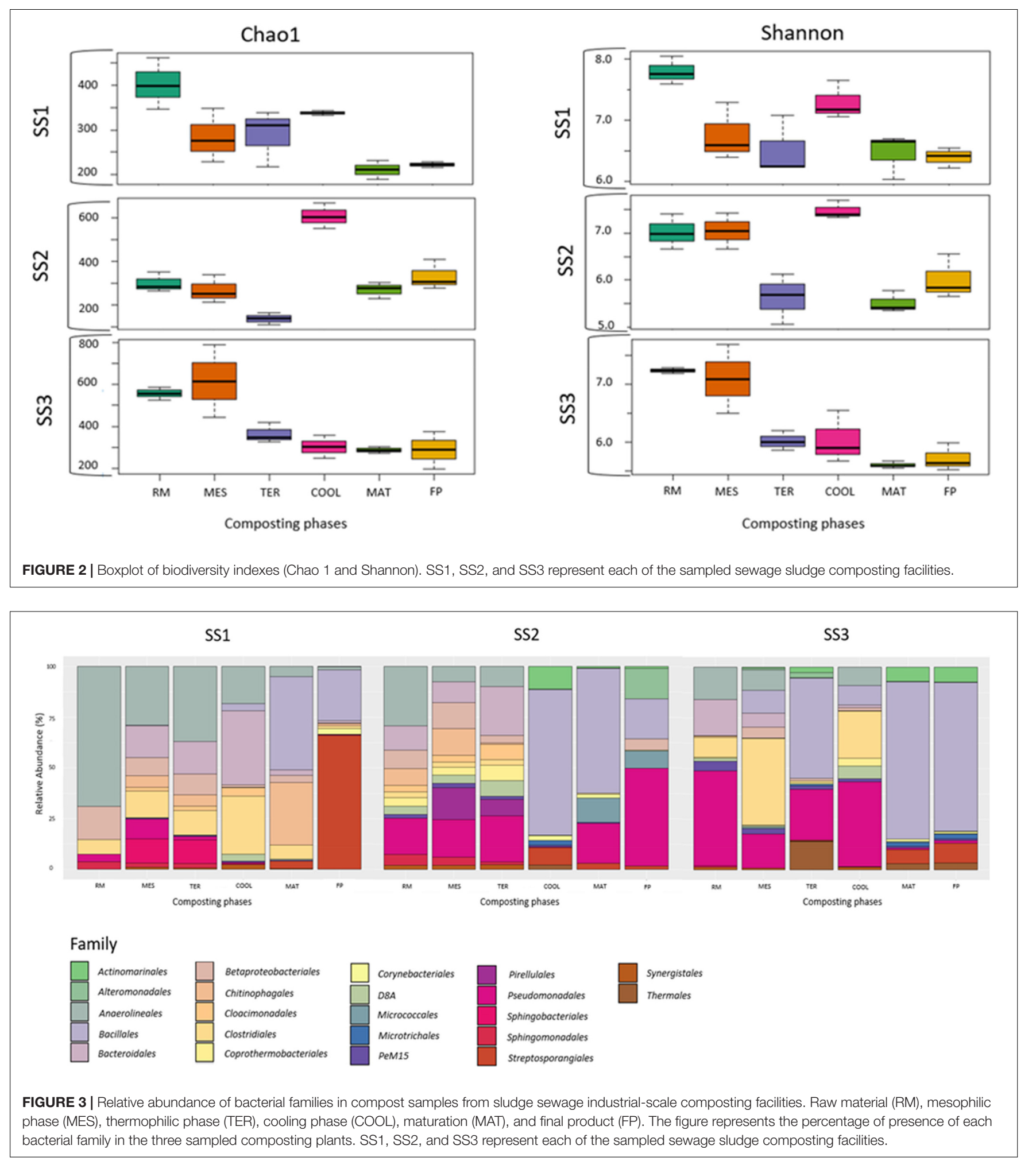

from an evolutionary point of view, establishing continuity and logical boundaries between the three main phases of the process. In the second discriminant analysis (Figure 4B), two discriminant functions responsible for $100 \%$ of the variability of the data were presented. According to these results, it is clear that the data related to monitoring parameters, biodiversity indices, and abundance of the majority families were grouped separately according to development of each facility.

On the other hand, a Pearson correlation analysis was elaborated to check the relationship between the different 


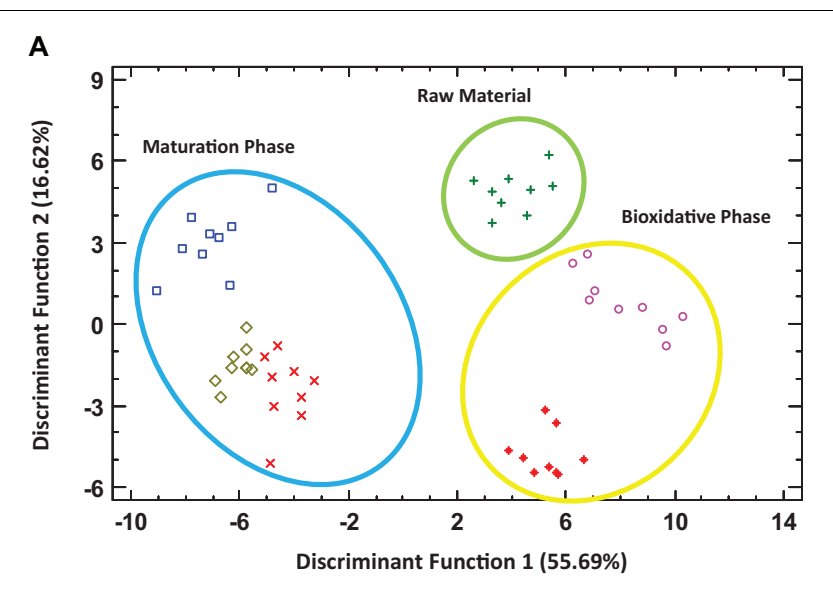

B

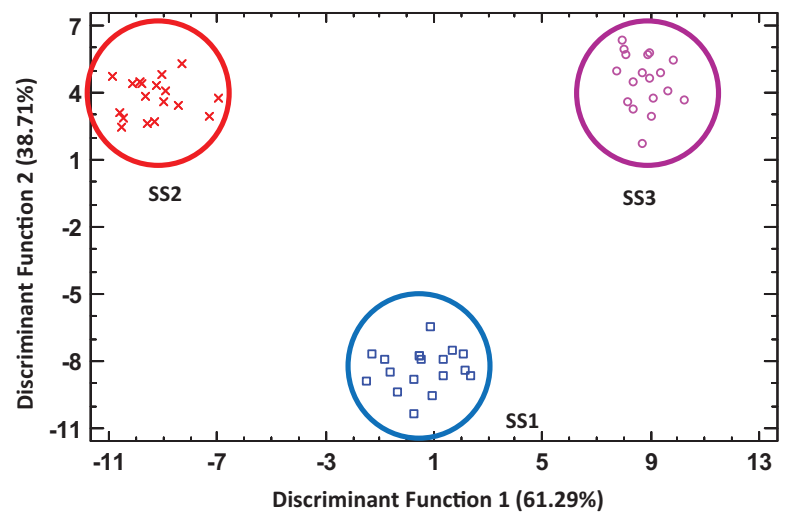

FIGURE 4 | Discriminant analysis based on composting of different sewage sludge processes, taking into account the monitoring parameters, biodiversity indices, and abundance of majority families. Panel (A) represents the data as a function of composting phases; Panel (B) represents the data as a function of the facilities sampled.

parameters studied and the bacterial microbiota of the samples (Figure 5). The higher the correlation between the two parameters, the larger the size of the circle. The most significant values $(p<0.05)$ were the positive correlation between Sphingomonodales and Betaproteobacteriales (0.83) as well as Anaerolineales with respect to organic matter (0.55) and Bacteroidales (0.50). In contrast, the most significant negative correlations were those between Bacillales and Bacteroidales $(-0.58)$, organic matter $(-0.64)$, and Anaerolineales $(-0.62)$ and the one presented by BD with respect to moisture $(-0.69)$ and organic matter $(-0.54)$.

\section{Antibiotic Susceptibility}

The group of strains collected from fecal contamination analytics was composed of a total of 19 isolates, represented in Table 2. The vast majority were recorded before reaching thermophilic conditions in the compost piles (16 of the 19 isolates). The group with the highest representation in the collection was fecal coliforms, with up to 14 isolates, followed by 3 strains from the fecal enterococci group and two strains of Salmonella. There was a clear decrease in the number of strains once thermophilic conditions were established. In fact, only R19 was isolated in the maturation phase. Moreover, no strain was isolated from the final stage of the process.

The results of the antibiotic susceptibility are represented in Figure 6. The antimicrobials that had a greater antibiotic effect and inhibited the growth of the majority of the strains were ciprofloxacin, imipenem, and streptomycin, with an approximate average of growth inhibition halo of 34,34 , and $25 \mathrm{~mm}$, respectively. By contrast, amoxicillin was the less effective antibiotic given that 11 out of 19 strains were resistant to this compound. The isolates showed resistance to at least one antibiotic. However, the strain belonging to fecal enterococci, R16, showed resistance to azithromycin, kanamycin, and amoxicillin.

\section{DISCUSSION}

\section{Development of the Industrial Composting}

Composting requires an exhaustive control of the different parameters that affect the process. This is necessary in order to obtain a final product with high quality that allows it to be used safely and efficiently (Siles-Castellano et al., 2020). In this sense, a moisture around $50-60 \%$ in the material is crucial to ensuring the correct proliferation of microorganisms (Jurado et al., 2020). The raw materials analyzed showed moisture values suitable for demands of the aerobic microbiota until they ended up at around $30 \%$ in SS2 and SS3 (Figure 1). However, in SS1 the final content of this parameter was too low, due to the lack of irrigation of the pile. This was a punctual fact since during the composting process, a correct humectation was provided. Regarding organic matter, a decrease at the start of the maturation phase, similar to that by Fialho et al. (2010), was observed. Thus, the percentages were according to the European Union regulation (EU, 2019). The temperature recorded during the process informs about the stabilization of the material and the degradation of the organic matter (Estrella-González et al., 2019). In all facilities, at the thermophilic phase the temperature was higher than $65^{\circ} \mathrm{C}$. This is essential because temperatures above $50^{\circ} \mathrm{C}$ during, at least, 7 days ensure the sanitation of materials (Zhu et al., 2016). The $\mathrm{pH}$ in the compost obtained in all facilities was adequate for the agronomic use of the compost (Bernal et al., 2017; Azim et al., 2018). Based on Awasthi et al. (2014) and Chowdhury et al. (2015), an electrical conductivity of $4 \mathrm{mS} \mathrm{cm}^{-1}$ in the final product is appropriate. With the exception of SS2, in both SS1 and SS3, data around the above were recorded (Figures $\mathbf{1 B}, \mathbf{F}$ ). The $\mathrm{C} / \mathrm{N}$ ratio affects directly to the process development, and the initial optimal $\mathrm{C} / \mathrm{N}$ ratio is 25-30 (Estrella-González et al., 2020a). Nevertheless, the facilities analyzed started with a lower value of the $\mathrm{C} / \mathrm{N}$ ratio. This is because sewage sludge has a high amount of nitrogen (Witter and Lopez-Real, 1987) and the initial mixtures were not ideal. These low $\mathrm{C} / \mathrm{N}$ values can cause a loss of nitrogen during the process (Zhang et al., 2016). BD values close to $0.2-0.35 \mathrm{~g} \mathrm{~cm}^{-3}$ are considered correct for composting (Chang et al., 2019). In this sense, BD data of SS1, SS2, and SS3 complied with the above 


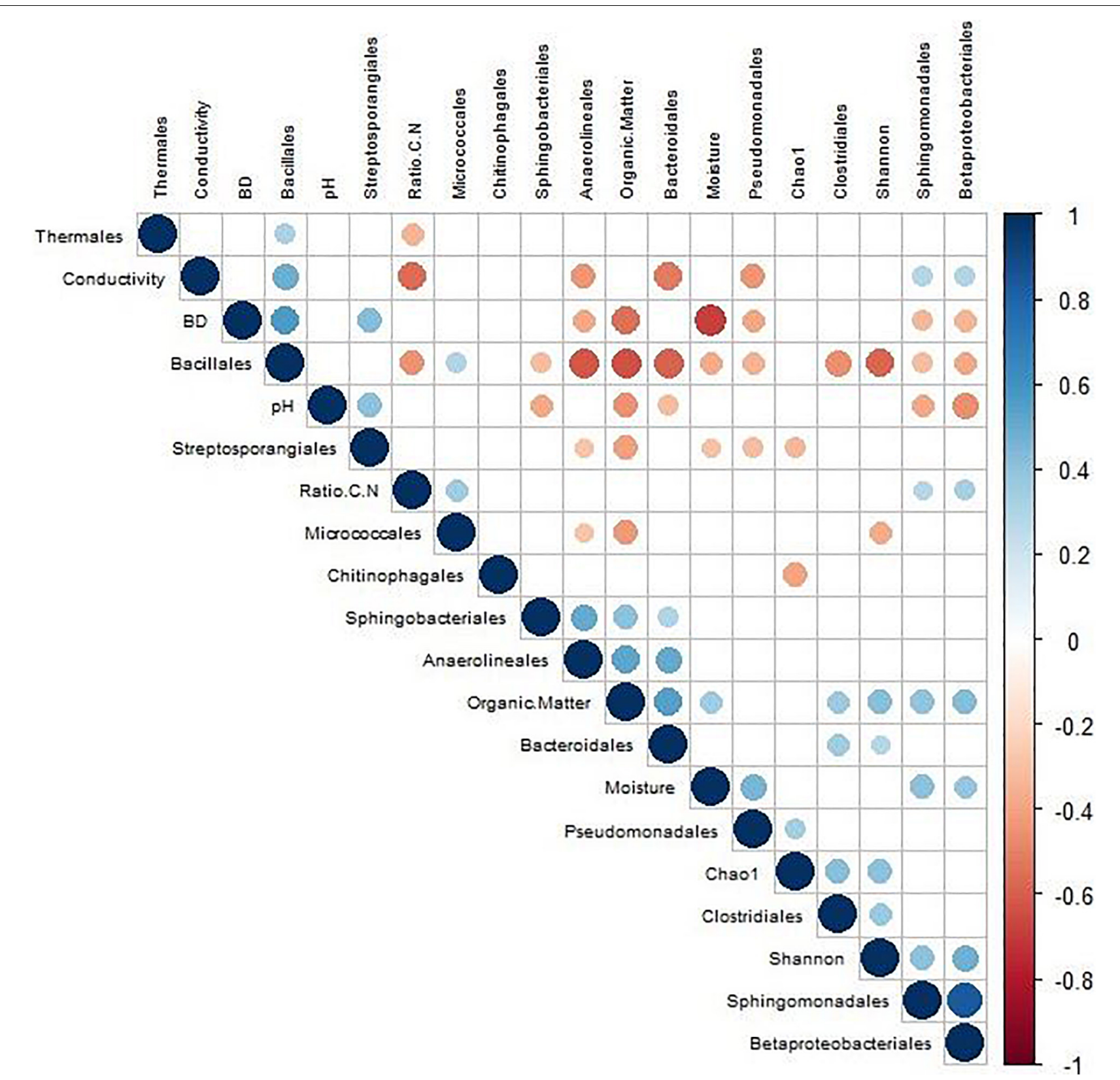

FIGURE 5 | Pearson's correlation analysis based on composting of different sewage sludge processes, taking into account the monitoring parameters, biodiversity indices, and most important families.

and showed the typical increase in that parameter while organic matter was being degraded.

\section{Fecal Indicators}

The agronomic applications of the final products of the composting process make it necessary to ensure sanitation during the different phases. For this purpose, fecal indicators are adequate to determine the sanitary quality of the composts obtained (Manga et al., 2021). According to EU Regulation 2019/1009 (EU, 2019), E. coli or fecal enterococci counts must be less than $1,000 \mathrm{cfu} \mathrm{g}^{-1}\left[\log \left(\mathrm{cfu} \mathrm{g}^{-1}\right)<3\right]$ in final products.
Moreover, Salmonella has to be absent in $25 \mathrm{~g}$ of compost. The results of the evaluation of the fecal contamination, as shown in Table 2, demonstrated that the fecal indicators evaluated were well below the limit indicated by the legislation. In fact, E. coli was only detected in the mesophilic phase. The temperature reached once thermophilic conditions were established was not suitable for the proliferation of this species (Santos et al., 2020). In the case of fecal enterococci, which have higher survival capacity, the levels were above the coliform group. This group overcame the range of $1,000 \mathrm{cfu}^{-1}$ in the MES phase. Nevertheless, at the end of the process, the counts were lower than the 
TABLE 2 | Group of strains isolated of each positive result of the fecal contamination during the composting process in SS1 with its codes.

\begin{tabular}{|l|c|c|}
\hline Strain & Microbial group & Composting phase \\
\hline R1 & Fecal coliform & \\
R2 & & \\
R3 & & \\
R4 & & \\
R5 & & \\
R6 & & \\
R7 & & \\
R8 & & \\
R9 & & \\
R10 & & \\
R11 & & \\
R12 & & \\
R13 & & \\
R14 & & MAT \\
R15 & & \\
R16 & & \\
\hline R17 & & \\
R18 & & \\
\hline R19 & & \\
\hline
\end{tabular}

threshold set by the regulation (EU, 2019). These results are consistent with the research of Ozdemir et al. (2020), in which the fecal enterococci load decreased due to increased temperature. With regard to sulfite-reducing clostridia, these are only able to proliferate in anaerobic habitats. Therefore, as composting is an aerobic process, it impeded the growth of this group. Matiz-Villamil et al. (2021) observed a similar trend to that recorded in the present study. These authors found that the counts of Clostridium spp. decreased due to the toxic effect that the oxygen had in this genus. This could explain the lower counts compared to the other indicators of fecal contamination. The detection of Salmonella in TER and COOL samplings was not as expected since these pathogens are unable to proliferate above $60^{\circ} \mathrm{C}$ (Fatunla et al., 2017). In addition to the effect of temperature, Salmonella can also be eliminated by the microbiota present in the pile (El Hayani et al., 2021). The addition of fresh material could have caused the detection of this pathogen at these stages. The presence of Listeria in sewage sludge is quite frequent (Lasaridi et al., 2018; Gholipour et al., 2020). In the case of SS1, Listeria was not detected by either cultivar or culture-independent techniques throughout the process. This genus includes two species pathogenic to humans, L. ivanovii and L. monocytogenes (Luque-Sastre et al., 2018). Thus, its absence in the final product would indicate good sanitization since it is not a microorganism with high thermotolerance (Bilung et al., 2018).

\section{S rRNA Phylogeny Comparative and Statistical Analysis}

One of the main problems in comparing the metagenomics results obtained is the large number of bioinformatics tools available. This can lead to different results depending on the algorithms used to calculate the different biodiversity indices (Prodan et al., 2020). Despite this, coincidences can be observed
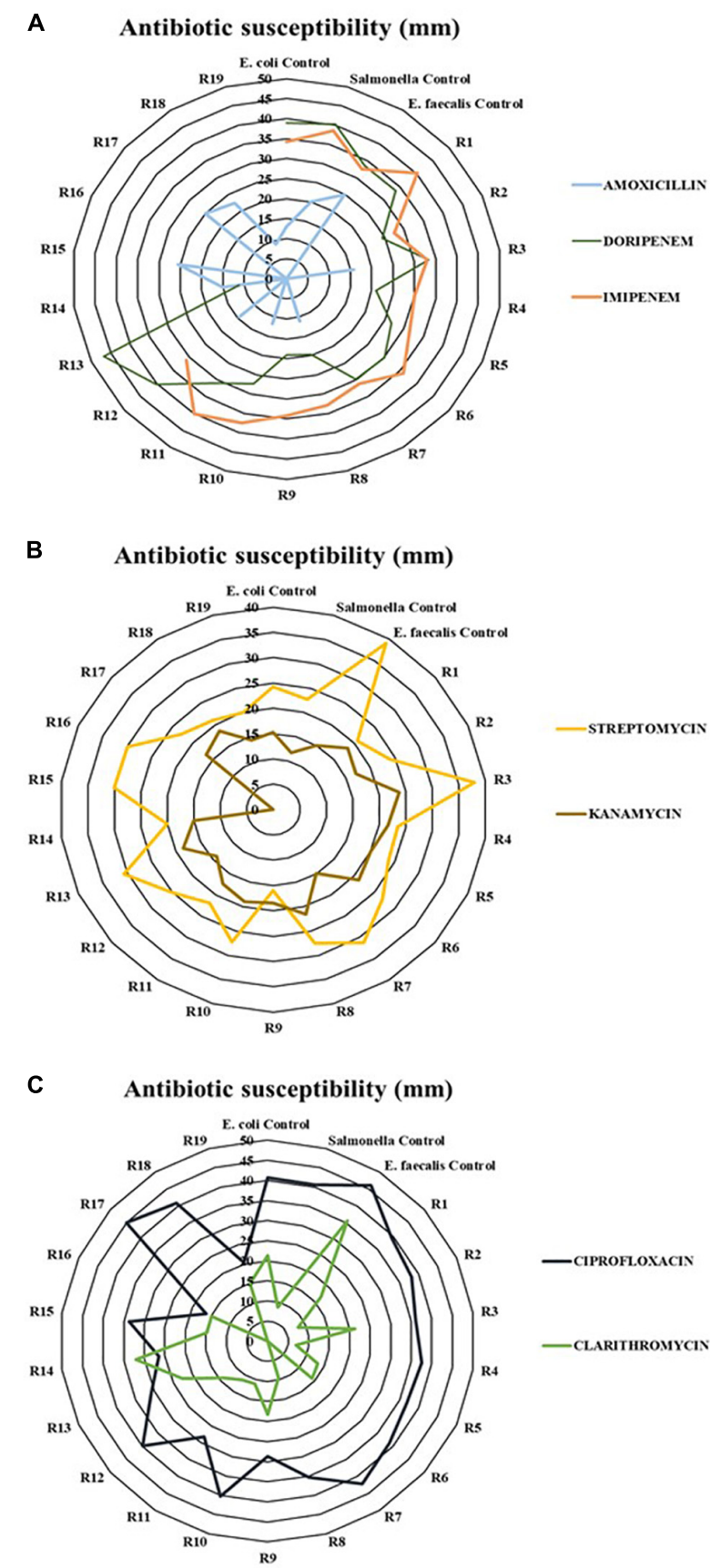

FIGURE 6 | Antibiotic characterization of the strains obtained and the three controls used (E. coli ATCC 13706; Salmonella ATCC 10708; E. faecalis ATCC 33186). Panel (A) represents beta-lactam antibiotics; Panel (B) represents aminoglycoside antibiotics; and Panel (C) represents quinolone and macrolide antibiotics. 
environment for microbiota proliferation, probably due to the limited access to the carbon present. In another composting process elaborated with poultry manure and rice straw (Zainudin et al., 2020), the values of the Shannon index oscillated in the same range to those presented by the three facilities studied. In accordance with the results of Lv et al. (2015) based on the stability of the mixture of sewage sludge and cattle manure, the abundance of the analyzed samples decreased as the process progressed, which supports the data obtained for the Shannon index. In the present study, the similarity between the values of MAT (5.87 Shannon index value) and FP (6.05 Shannon index value) of the statistical analysis indicated that most of the detected bacterial microbiota was maintained until the end of the process (Figure 2). This trend was also observed in the studies of López-González et al. (2015), in which the bacterial community structure was preserved in both the maturation phase and the compost.

According to Cai et al. (2018), it is usual to find mostly members of the phylum Proteobacteria in composts made from sewage sludge. These data coincide with those obtained in SS2 (Figure 3). The presence in the compost of populations belonging to the phylum Actinobacteria, as in the case of SS1, is indicative of stabilization and maturation of the materials generated. This is because Actinobacteria species participate in the biodegradation of recalcitrant compounds and lignocelluloses, thus playing an important role in the last phase of composting (Cao et al., 2021). Gram-negative Bacteroidetes are the group of anaerobic bacteria whose main function in the fermentation system is to break down macromolecules (such as proteins, starches, cellulose, and fibrous substances). The decrease in abundance of this group throughout the process is attributed to the reduction in the amounts of readily usable proteins and carbohydrates (Cai et al., 2018), but above all to the persistence of aerobic and thermophilic environments in the compost piles. The order Bacillales belongs to the phylum Firmicutes and plays an important role in lignocellulose degradation in these environments (Li et al., 2019), due to its high thermotolerance (Moreno et al., 2021). Thus, it was expected that as composting processes develop, this group would gain predominance. Indeed, this is what happened. This phylum was the majority in all facilities, especially in SS3. Moreover, most of the orders found in the different phases coincide with those described by Silva et al. (2016).

In order to achieve a correct interpretation of the data, it is not sufficient to read the results ascribed to the microbiome present throughout the industrial processes. Therefore, in the present study, a statistical analysis was integrated to evaluate the interaction between biological and physicochemical parameters (Figures 4, 5). These statistical data provided a true reflection of the evolution of composting. According to the information provided by discriminant analysis, it can be extracted that despite of the specificity of the evolution of the bacteriome in each facility, all of them present a development by which they end up converging in adequate stabilized products. This behavior has been previously described in industrial processes both from a physicochemical (Siles-Castellano et al., 2020) and microbiological (Estrella-González et al., 2020b) point of view. In this sense, Pearson's correlations reflected an interesting relationship between the variables that mark the development of the composting process (organic matter and $\mathrm{BD}$ ) with the disappearance of certain microbial groups that are not described as resident microbiota of the process but as part of untreated organic waste. Moreover, the opposite effect was produced in those groups that were found to be adapted to the process (Bacillales and Streptosporongiales). In summary, the behavior of the 16S rRNA phylogeny indicators used in the study show a loss of biodiversity associated with groups considered as part of the transient microbiota of the composting process (including microbiota associated with fecal contamination). This leads to an enrichment in resident populations of the compost, as it has already been reported by previous works of our research group (López-González et al., 2015). However, now the results possess the precision provided by the $16 \mathrm{~S}$ rRNA phylogeny approach.

\section{Antibiotic Resistance}

With the aim of corroborating that composting can control the spread of ARGs (Li et al., 2020; Wei et al., 2020a), the antibiotic resistance of a collection of bacterial isolates from compost was characterized in this study. Each strain, shown in Table 2, was isolated from the positive results of fecal evaluation. The majority of strains came from mesophilic phase sampling. However, when the thermophilic stage reached, there was a decrease in the number and diversity of isolates. This was clearly observed in the case of the fecal coliform group. These results are in concordance with the studies of Youngquist et al. (2016), Wang et al. (2018), and Arthurson (2020), where the microbial community, including pathogens, was reduced along the process because conditions were not suitable for the microbial growth. In sewage sludge, due to its anthropogenic origin, microbiota with ARGs and traces of antimicrobial compounds can be easily found (Wei et al., 2020b; Chen et al., 2021). Moreover, according to Wang et al. (2017), those bacteria that do not present resistance can acquire it through mobile genetic elements (MGEs). Therefore, without precise control of these wastes, the resistant bacteria present in them can be spread into the environment. Based on the results of the antibiogram, represented in Figure 6, strains isolated showed some resistance. In fact, amoxicillin was the least effective antibiotic since 11 of the 19 strains showed resistance to this compound. Liu et al. (2021) also reported the presence of microorganisms isolated of manures resistant to this antibiotic. The extensive use of amoxicillin in both humans and animals has increased resistance to this compound (Sodhi et al., 2021). On the other hand, most strains were sensitive to ciprofloxacin, streptomycin, and imipenem. However, none of the microorganisms were isolated from the final product. Thus, composting plays an important role in the elimination of ARGs. This is a possible approach to mitigate the damage of increasing antibacterial resistance.

\section{CONCLUSION}

According to the results of the present study, the industrial composting of sewage sludge managed to generate a final product 
that complies with the hygienic-sanitary quality required by current legislation. During the bio-oxidative phase of the process, the values related to fecal contamination indicators carrying ARGs were significantly reduced, to the benefit of a resident microbiota adapted to the prevailing conditions. In the sewage sludge, there were numerous microorganisms of fecal origin that showed resistance to antibiotics routinely used in humans. Such resistances were detected mainly in microbial strains isolated from raw materials and the bio-oxidative phase of the process. Therefore, industrial-scale sewage sludge composting was shown to be an effective tool for the elimination of indicator strains of fecal contamination resistant to certain antibiotics in routine use. Thus, it contributed to the reduction of the spread of ARGs in environmental microbiomes, as well as the transfer of the same in the food chain.

\section{DATA AVAILABILITY STATEMENT}

The datasets presented in this study can be found in online repositories. The names of the repository/repositories and

\section{REFERENCES}

Abadi, A. T. B., Rizvanov, A. A., Haertlé, T., and Blatt, N. L. (2019). World health organization report: current crisis of antibiotic resistance. Bionanoscience 9, 778-788. doi: 10.1007/s12668-019-00658-4

Abuşoğlu, A., Özahi, E., Kutlar, A. Í, and Al-jaf, H. (2017). Life cycle assessment (LCA) of digested sewage sludge incineration for heat and power production. J. Clean. Prod. 142, 1684-1692. doi: 10.1016/j.jclepro.2016.11.121

Andrews, S. (2010). FastQC: A Quality Control Tool for High Throughput Sequence data. Available online at: http://www.bioinformatics.babraham.ac.uk/projects/ fastqc (accessed July 15, 2021)

Arthurson, V. (2020). Proper sanitation of sewage sludge: a critical issue for a sustainable society. Appl. Environ. Microbiol. 74:17. doi: 10.1128/AEM.004 38-08

Awasthi, M. K., Pandey, A. K., Khan, J., Bundela, P. S., Wong, J. W. C., and Selvam, A. (2014). Evaluation of thermophilic fungal consortium for organic municipal solid waste composting. Bioresour. Technol. 168, 214-221. doi: 10. 1016/j.biortech.2014.01.048

Azim, K., Soudi, B., Boukhari, S., Perissol, C., Roussos, S., and Alami, I. T. (2018). Composting parameters and compost quality: a literature review. Organ. Agric. 8, 141-158. doi: 10.1007/s13165-017-0180-z

Bauer, A. W., Kirby, W. M., Sherris, J. C., and Turck, M. (1966). Antibiotic susceptibility testing by a standardized single disc method. Am. J. Clin. Pathol. 45, 493-496. doi: 10.1093/ajcp/45.4_ts.493

Bernal, M. P., Sommer, S. G., Chadwick, D., Chen, Q., Li, G. Jr., and Michel, F. C. (2017). "Chapter three - current approaches and future trends in compost quality criteria for agronomic, environmental and human health benefits," in Advances in Agronomy, Vol. 144, ed. D. L. Sparks (Cambridge, MA: Academic Press), 143-233. doi: 10.1016/bs.agron.2017.03.002

Bilung, L. M., Chai, L. S., Tahar, A. S., Ted, C. K., and Apun, K. (2018). Prevalence, genetic heterogeneity, and antibiotic resistance profile of Listeria spp. and Listeria monocytogenes at farm level: a highlight of eric- and box-pcr to reveal genetic diversity. Biomed Res. Int. 2018:3067494. doi: 10.1155/2018/3067494

Bolyen, E., Rideout, J. R., Dillon, M. R., Bokulich, N. A., Abnet, C. C., AlGhalith, G. A., et al. (2019). Reproducible, interactive, scalable and extensible microbiome data science using QIIME 2. Nat. Biotechnol. 37, 852-857. doi: 10.1038/s41587-019-0209-9

Cai, L., Gong, X., Sun, X., Li, S., and Yu, X. (2018). Comparison of chemical and microbiological changes during the aerobic composting and vermicomposting of green waste. PLoS One 13:e0207494. doi: 10.1371/journal.pone.0207494 accession number(s) can be found below: https://www.ncbi.nlm. nih.gov/, PRJNA769273.

\section{AUTHOR CONTRIBUTIONS}

JL-G: formal analyses, investigation, supervision, and writingoriginal draft preparation. ME-G: investigation and writingoriginal draft preparation. RL-M: methodology, investigation, formal analyses, and writing-original draft preparation. MJ and FS-E: methodology and investigation. ML: methodology, visualization, supervision, and writing-review and editing. All authors contributed to the article and approved the submitted version.

\section{FUNDING}

This work was financially supported by the Spanish Ministerio de Economía y Competitividad through the project AGL201564512R.

Callahan, B. J., McMurdie, P. J., Rosen, M. J., Han, A. W., Johnson, A. J. A., and Holmes, S. P. (2016). DADA2: high-resolution sample inference from Illumina amplicon data. Nat. Methods 13:581. doi: 10.1038/nmeth.3869

Cao, L., Liao, L., Su, C., Mo, T., Zhu, F., Qin, R., et al. (2021). Metagenomic analysis revealed the microbiota and metabolic function during co-composting of food waste and residual sludge for nitrogen and phosphorus transformation. Sci. Total Environ. 773:145561. doi: 10.1016/j.scitotenv.2021.145561

Chang, R., Guo, Q., Chen, Q., Bernal, M. P., Wang, Q., and Li, Y. (2019). Effect of initial material bulk density and easily-degraded organic matter content on temperature changes during composting of cucumber stalk. J. Environ. Sci. 80, 306-315. doi: 10.1016/j.jes.2017.10.004

Chen, Z., Li, Y., Ye, C., He, X., and Zhang, S. (2021). Fate of antibiotics and antibiotic resistance genes during aerobic co-composting of food waste with sewage sludge. Sci. Total Environ. 784:146950. doi: 10.1016/j.scitotenv.2021. 146950

Chowdhury, A. K. M. M. B., Konstantinou, F., Damati, A., Akratos, C. S., Vlastos, D., Tekerlekopoulou, A. G., et al. (2015). Is physicochemical evaluation enough to characterize olive mill waste compost as soil amendment? The case of genotoxicity and cytotoxicity evaluation. J. Clean. Prod. 93, 94-102. doi: 10. 1016/j.jclepro.2015.01.029

Eid, E. M., Alrumman, S. A., El-Bebany, A. F., Fawy, K. F., Taher, M. A., Hesham, A. E. L., et al. (2018). The evaluation of sewage sludge application as a fertilizer for broad bean (Faba sativa Bernh.) crops. Food Energy Secur. 7:e00142. doi: $10.1002 /$ fes 3.142

El Hayani, B., El Fels, L., Ouhdouch, Y., and Hafidi, M. (2021). Fate of pathogenic microorganisms during lagooning sludge composting and exploration of bacteriophages as indicator of hygienization. Environ. Technol. Innov. 21:101268. doi: 10.1016/j.eti.2020.101268

Estrella-González, M. J., Jurado, M. M., Suárez-Estrella, F., López, M. J., LópezGonzález, J. A., Siles-Castellano, A. B., et al. (2019). Enzymatic profiles associated with the evolution of the lignocellulosic fraction during industrialscale composting of anthropogenic waste: comparative analysis. J. Environ. Manage. 248:109312. doi: 10.1016/j.jenvman.2019.109312

Estrella-González, M. J., López-González, J. A., Suarez-Estrella, F., López, M. J., Jurado, M. M., Siles-Castellano, A. B., et al. (2020a). Evaluating the influence of raw materials on the behavior of nitrogen fractions in composting processes on an industrial scale. Bioresour. Technol. 303:122945. doi: 10.1016/j.biortech. 2020.122945

Estrella-González, M. J., Suárez-Estrella, F., Jurado, M. M., López, M. J., LópezGonzález, J. A., Siles-Castellano, A. B., et al. (2020b). Uncovering new indicators 
to predict stability, maturity and biodiversity of compost on an industrial scale. Bioresour. Technol. 313:123557. doi: 10.1016/j.biortech.2020.123557

EU (2019). Regulation (EU) 2019/1009 of the European Parliament and of the Council of 5 June 2019 Laying Down Rules on the Making Available on the Market of EU Fertilising Products and Amending. Regulations (EC) No 1069/2009 and (EC) No 1107/2009 and Repealing Regulation (EC) No 2003/2003. Brussels: EU.

Fatunla, K., Inam, E., Essien, J., Dan, E., Odon, A., Kang, S., et al. (2017). Influence of composting and thermal processing on the survival of microbial pathogens and nutritional status of Nigeria sewage sludge. Int. J. Recycl. Organ. Waste Agric. 6, 301-310. doi: 10.1007/s40093-017-0177-3

Fialho, L. L., Silva, W. T. L. D., Milori, D. M. B. P., Simoes, M. L., and Martin-Neto, L. (2010). Characterization of organic matter from composting of different residues by physicochemical and spectroscopic methods. Bioresour. Technol. 101, 1927-1934. doi: 10.1016/j.biortech.2009.10.039

Gao, N., Kamran, K., Quan, C., and Williams, P. T. (2020). Thermochemical conversion of sewage sludge: a critical review. Prog. Energy Combust. Sci. 79:100843. doi: 10.1016/j.pecs.2020.100843

Gholipour, S., Nikaeen, M., Farhadkhani, M., and Nikmanesh, B. (2020). Survey of Listeria monocytogenes contamination of various environmental samples and associated health risks. Food Control 108:106843. doi: 10.1016/j.foodcont.2019. 106843

He, Y., Yuan, Q., Mathieu, J., Stadler, L., Senehi, N., Sun, R., et al. (2020). Antibiotic resistance genes from livestock waste: ocurrence, dissemination, and treatment. NPJ Clean Water 3:4. doi: 10.1038/s41545-020-0051-0

Huong, L. Q., Forslund, A., Madsen, H., and Dalsgaard, A. (2014). Survival of Salmonella spp. and fecal indicator bacteria in Vietnamese biogas digesters receiving pig slurry. Int. J. Hyg. Environ. Health 217, 785-795. doi: 10.1016/j. ijheh.2014.04.004

Jurado, M. M., Camelo-Castillo, A. J., Suárez-Estrella, F., López, M. J., LópezGonzález, J. A., Estrella-González, M. J., et al. (2020). Integral approach using bacterial microbiome to stabilize municipal solid waste. J. Environ. Manage. 265:110528. doi: 10.1016/j.jenvman.2020.110528

Kacprzak, M., Neczaj, E., Fijałkowski, K., Grobelak, A., Grosser, A., Worwag, M., et al. (2017). Sewage sludge disposal strategies for sustainable development. Environ. Res. 156, 39-46. doi: 10.1016/j.envres.2017.03.010

Karkman, A., Do, T. T., Walsh, F., and Virta, M. P. J. (2018). Antibiotic-resistance genes in waste water. Trends Microbiol. 26, 220-228. doi: 10.1016/j.tim.2017. 09.005

Lamastra, L., Suciu, N. A., and Trevisan, M. (2018). Sewage sludge for sustainable agriculture: contaminants' contents and potential use as fertilizer. Chem. Biol. Technol. Agric. 5:10. doi: 10.1186/s40538-018-0122-3

Lasaridi, K. E., Manios, T., Stamatiadis, S., Chroni, C., and Kyriacou, A. (2018). The evaluation of hazards to man and the environment during the composting of sewage sludge. Sustainability 10:2618. doi: 10.3390/su10082618

Li, C., Li, H., Yao, T., Su, M., Ran, F., Han, B., et al. (2019). Microbial inoculation influences bacterial community succession and physicochemical characteristics during pig manure composting with corn straw. Bioresour. Technol. 289:121653. doi: 10.1016/j.biortech.2019.121653

Li, K., Cao, R., Mo, S., Yao, R., Ren, Z., and Wu, J. (2020). Swine manure composting with compound microbial inoculants: removal of antibiotic resistance genes and their associations with microbial community. Front. Microbiol. 11:592592. doi: 10.3389/fmicb.2020.592592

Liu, N., Xu, L., Han, L., Huang, G., and Ciric, L. (2021). Microbiological safety and antibiotic resistance risks at a sustainable farm under large-scale openair composting and composting toilet systems. J. Hazard. Mater. 401:123391. doi: 10.1016/j.jhazmat.2020.123391

López-González, J. A., Suárez-Estrella, F., Vargas-García, M. C., López, M. J., Jurado, M. M., and Moreno, J. (2015). Dynamics of bacterial microbiota during lignocellulosic waste composting: studies upon its structure, functionality and biodiversity. Bioresour. Technol. 175, 406-416. doi: 10.1016/j.biortech.2014. 10.123

Luque-Sastre, L., Arroyo, C., Fox, E. M., McMahon, B. J., Bai, L., Li, F., et al. (2018). Antimicrobial resistance in Listeria species. Microbiol. Spectr. 6, 1-23. doi: 10.1128/microbiolspec.ARBA-0031-2017

Lv, B., Xing, M., Yang, J., and Zhang, L. (2015). Pyrosequencing reveals bacterial community differences in composting and vermicomposting on the stabilization of mixed sewage sludge and cattle dung. Appl. Microbiol. Biotechnol. 99, 10703-10712. doi: 10.1007/s00253-015-6884-7
Ma, C., Lo, P. K., Xu, J., Li, M., Jiang, Z., Li, G., et al. (2020). Molecular mechanisms underlying lignocellulose degradation and antibiotic resistance genes removal revealed via metagenomics analysis during different agricultural wastes composting. Bioresour. Technol. 314:123731. doi: 10.1016/j.biortech. 2020.123731

Magoč, T., and Salzberg, S. L. (2011). FLASH: fast length adjustment of short reads to improve genome assemblies. Bioinformatics 27, 2957-2963. doi: 10.1093/ bioinformatics/btr507

Manga, M., Camargo-Valero, M. A., Anthonj, C., and Evans, B. E. (2021). Fate of faecal pathogen indicators during faecal sludge composting with different bulking agents in tropical climate. Int. J. Hyg. Environ. Heal. 232:113670. doi: 10.1016/j.ijheh.2020.113670

Matiz-Villamil, A., Chamorro-Tobar, I. C., Sáenz-Aponte, A., Pulido-Villamarín, A., Carrascal-Camacho, A. K., Gutiérrez-Rojas, I. S., et al. (2021). Management of swine mortalities through the use of a mixed composting-accelerating bioinoculant. Heliyon 7:e05884. doi: 10.1016/j.heliyon.2020.e05884

Mobarki, N. S., Almerabi, B. A., and Hattan, A. H. (2019). Antibiotic resistance crisis. IJMDC 3, 561-564. doi: 10.24911/IJMDC.51-1549060699

Moreno, J., López-González, J. A., Arcos-Nievas, M. A., Suárez-Estrella, F., Jurado, M. M., Estrella-González, M. J., et al. (2021). Revisiting the succession of microbial populations throughout composting: a matter of thermotolerance. Sci. Total Environ. 773:145587. doi: 10.1016/j.scitotenv.2021.145587

Ozdemir, S., Yetilmezsoy, K., Dede, G., and Sazak, M. (2020). Application of solarization for sanitization of sewage sludge compost. J. King Saud Univ. Sci. 32, 443-449. doi: 10.1016/j.jksus.2018.07.004

Prodan, A., Tremaroli, V., Brolin, H., Zwinderman, A. H., Nieuwdorp, M., and Levin, E. (2020). Comparing bioinformatic pipelines for microbial $16 \mathrm{~S}$ rRNA amplicon sequencing. PLoS One 15:e0227434. doi: 10.1371/journal.pone. 0227434

Raheem, A., Sikarwar, V. S., He, J., Dastyar, W., Dionysiou, D. D., Wang, W., et al. (2018). Opportunities and challenges in sustainable treatment and resource reuse of sewage sludge: a review. Chem. Eng. Sci. 337, 616-641. doi: 10.1016/ j.cej.2017.12.149

Razza, F., D’Avino, L., L'Abate, G., and Lazzeri, L. (2018). "The role of compost in bio-waste management and circular economy," in Designing Sustainable Technologies, Products and Policies, eds E. Benetto, K. Gericke, and M. Guiton (Cham: Springer), 133-143. doi: 10.1007/978-3-319-66981-6_16

Rubin, E. M. (2008). Genomics of cellulosic biofuels. Nature 454, 841-845. doi: 10.1038 /nature 07190

Santos, A. F., Santos, C. P., Matos, A. M., Cardoso, O., and Quina, M. J. (2020). Effect of thermal drying and chemical treatments with wastes on microbiological contamination indicators in sewage sludge. Microorganisms 8:376. doi: 10.3390/microorganisms8030376

Siles-Castellano, A. B., López, M. J., Jurado, M. M., Suárez-Estrella, F., LópezGonzález, J. A., Estrella-González, M. J., et al. (2020). Industrial composting of low carbon/nitrogen ratio mixtures of agri-food waste and impact on compost quality. Bioresour. Technol. 316:123946. doi: 10.1016/j.biortech.2020.123946

Silva, M. E. F., Lopes, A. R., Cunha-Queda, A. C., and Nunes, O. C. (2016). Comparison of the bacterial composition of two commercial composts with different physicochemical, stability and maturity properties. Waste Manag. 50, 20-30. doi: 10.1016/j.wasman.2016.02.023

Sodhi, K. K., Kumar, M., and Singh, D. K. (2021). Insight into the amoxicillin resistance, ecotoxicity, and remediation strategies. J. Water Process. Eng. 39:101858. doi: 10.1016/j.jwpe.2020.101858

Soobhany, N., Mohee, R., and Garg, V. V. (2017). Inactivation of bacterial pathogenic load in compost against vermicompost of organic solid waste aiming to achieve sanitation goals: a review. Waste Manage. 64, 51-62. doi: 10.1016/j. wasman.2017.03.003

Su, J. Q., Wei, B., Ou-Yang, W. Y., Huang, F. Y., Zhao, Y., Xu, H. J., et al. (2015). Antibiotic resistome and its association with bacterial communities during sewage sludge composting. Environ. Sci. Technol. 49, 7356-7363. doi: 10.1021/acs.est.5b01012

Sun, C., Li, W., Chen, Z., Qin, W., and Wen, X. (2019). Responses of antibiotics, antibiotic resistance genes, and mobile genetic elements in sewage sludge to thermal hydrolysis pre-treatment and various anaerobic digestion conditions. Environ. Int. 133:105156. doi: 10.1016/j.envint.2019.105156

Tang, Z., Huang, C., Tian, Y., Xi, B., Guo, W., and Tan, W. (2021). Fate of antibiotic resistance genes in industrial-scale rapid composting of pharmaceutical 
fermentation residue: the role implications of microbial community structure and mobile genetic elements. Environ. Pollut. 291:118155. doi: 10.1016/j.envpol. 2021.118155

Urra, J., Alkorta, I., Mijangos, I., Epelde, L., and Garbisu, C. (2019). Application of sewage sludge to agricultural soil increases the abundance of antibiotic resistance genes without altering the composition of prokaryotic communities. Sci. Total Environ. 647, 1410-1420. doi: 10.1016/j.scitotenv.2018.08.092

Wang, C., Dong, D., Strong, P. J., Zhu, W., Ma, Z., Qin, Y., et al. (2017). Microbial phylogeny determines transcriptional response of resistome to dynamic composting processes. Microbiome 5:103. doi: 10.1186/s40168-0170324-0

Wang, K., Mao, H., and Li, X. (2018). Functional characteristics and influence factors of microbial community in sewage sludge composting with inorganic bulking agent. Bioresour. Technol. 249, 527-535. doi: 10.1016/j.biortech.2017. 10.034

Wei, H., Ma, J., Su, Y., and Xie, B. (2020a). Effect of nutritional energy regulation on the fate of antibiotic resistance genes during composting of sewage sludge. Bioresour. Technol. 297:122513. doi: 10.1016/j.biortech.2019.122513

Wei, H., Ding, S., Qiao, Z., Su, Y., and Xie, B. (2020b). Insights into factors driving the transmission of antibiotic resistance from sludge compost-amended soil to vegetables under cadmium stress. Sci. Total Environ. 729:138990. doi: 10.1016/j.scitotenv.2020.138990

Witter, E., and Lopez-Real, J. M. (1987). The potential of sewage sludge and composting in a nitrogen recycling strategy for agriculture. Biol. Agric. Hortic. 5, 1-23. doi: 10.1080/01448765.1987.9755122

Wu, N., Xie, S., Zeng, M., Xu, X., Li, Y., Liu, X., et al. (2020). Impacts of pile temperature on antibiotic resistance, metal resistance and microbial community during swine manure composting. Sci. Total Environ. 744:140920. doi: 10.1016/j.scitotenv.2020.140920

Yadav, S., and Kapley, A. (2019). Exploration of activated sludge resistome using metagenomics. Sci. Total Environ. 692, 1155-1164. doi: 10.1016/j.scitotenv. 2019.07.267

Youngquist, C. P., Mitchell, S. M., and Cogger, C. G. (2016). Fate of antibiotics and antibiotic resistance during digestion and composting: a review. J. Environ. Qual. 45, 537-545. doi: 10.2134/jeq2015.05.0256

Zainudin, M. H., Mustapha, N. A., Maeda, T., Ramli, N., Sakai, K., and Hassan, M. (2020). Biochar enhanced the nitrifying and denitrifying bacterial communities during the composting of poultry manure and rice straw. Waste Manage. 106, 240-249. doi: 10.1016/j.wasman.2020.03.029

Zhang, J., Lin, H., Ma, J., Sun, W., Yang, Y., and Zhang, X. (2019). Compostbulking agents reduce the reservoir of antibiotics and antibiotic resistance genes in manures by modifying bacterial microbiota. Sci. Total Environ. 649, 396-404. doi: 10.1016/j.scitotenv.2018.08.212
Zhang, L., Li, L., Pan, X., Shi, Z., Feng, X., Gong, B., et al. (2018). Enhanced growth and activities of the dominant functional microbiota of chicken manure composts in the presence of maize straw. Front. Microbiol. 9:1131. doi: 10.3389/ fmicb.2018.01131

Zhang, M., He, L. Y., Liu, Y. S., Zhao, J. L., Zhang, J. N., Chen, J., et al. (2020). Variation of antibiotic resistome during commercial livestock manure composting. Environ. Int. 136:105458. doi: 10.1016/j.envint.2020.1 05458

Zhang, Y., Zhao, Y., Chen, Y., Lu, Q., Li, M., Wang, X., et al. (2016). A regulating method for reducing nitrogen loss based on enriched ammonia-oxidizing bacteria during composting. Bioresour. Technol. 221, 276-283. doi: 10.1016/j. biortech.2016.09.057

Zhu, P., Qin, H., Zhang, H., Luo, H., Ru, Y., Li, J., et al. (2021). Variations in antibiotic resistance genes and removal mechanisms induced by $\mathrm{C} / \mathrm{N}$ ratio of substrate during composting. Sci. Total Environ. 798:149288. doi: 10.1016/j. scitotenv.2021.149288

Zhu, Y. L., Zheng, G. D., Gao, D., Chen, T. B., Wu, F. K., Niu, M. J., et al. (2016). Odor composition analysis and odor indicator selection during sewage sludge composting. J. Air Waste Manag. Assoc. 66, 930-940. doi: 10.1080/10962247. 2016.1188865

Zittel, R., Da Silva, C. P., Domingues, C. E., Seremeta, D. C. H., da Cunha, K. M., and de Campos, S. X. (2020). Availability of nutrients, removal of nicotine, heavy metals and pathogens in compounds obtained from smuggled cigarette tobacco compost associated with industrial sewage sludge. Sci. Total Environ. 699:134377. doi: 10.1016/j.scitotenv.2019.134377

Conflict of Interest: The authors declare that the research was conducted in the absence of any commercial or financial relationships that could be construed as a potential conflict of interest.

Publisher's Note: All claims expressed in this article are solely those of the authors and do not necessarily represent those of their affiliated organizations, or those of the publisher, the editors and the reviewers. Any product that may be evaluated in this article, or claim that may be made by its manufacturer, is not guaranteed or endorsed by the publisher.

Copyright (c) 2021 López-González, Estrella-González, Lerma-Moliz, Jurado, SuárezEstrella and López. This is an open-access article distributed under the terms of the Creative Commons Attribution License (CC BY). The use, distribution or reproduction in other forums is permitted, provided the original author(s) and the copyright owner(s) are credited and that the original publication in this journal is cited, in accordance with accepted academic practice. No use, distribution or reproduction is permitted which does not comply with these terms. 